DOI: https//doi.org/10.13037/ci.vol22n50.7859

\title{
Ensino Remoto Emergencial em Jornalismo na pandemia do Covid 19: um relato de experiência de docentes da rede pública sobre as políticas de ensino em curso
}

\author{
Emergency Remote Teaching in Journalism in the Covid 19 pandemic: a report on the \\ experience of public university teachers on current education policies
}

\author{
Rafael Sbeghen Hoffai \\ ORCID: https://orcid.org/0000-0003-4745-5689 \\ Cristiane de Lima Barbosa ${ }^{\text {bii }}$ \\ ORCID: https://orcid.org/0000-0003-0358-4462
}

Recebido em 07/05/2021. Aprovado em: 27/08/2021.

Resumo

O trabalho descreve a prática do Ensino Remoto Emergencial (ERE) no curso de Jornalismo de uma universidade pública brasileira durante a pandemia do Covid-19 no ano de 2020. A prática de dois professores para a manutenção das atividades docentes e discentes utilizando Tecnologias de Informação e Comunicação (TIC) como instrumentos mediadores da prática de ensino-aprendizagem constitui o relato que serve como base para discutir as políticas públicas implementadas no plano educacional. Como percurso metodológico, o artigo contextualiza o ERE e discute as dificuldades e estratégias implementadas pelos docentes em contraste às resoluções institucionais vigentes. Como resultado são apontadas fragilidades e potencialidades dessa experiência.

Palavras-chave: Pandemia. Jornalismo. Ensino.

\begin{abstract}
The work describes the practice of Emergency Remote Teaching (ERE) in the Journalism course of a Brazilian public university during the Covid-19 pandemic in 2020. The practice of two professors for the maintenance of teaching and student activities using Information Technologies and Communication (ICTs) as mediating instruments of teaching-learning practice constitutes the report that serves as a basis for discussing public policies in the education. As a methodological approach, the article contextualizes the ERE and discusses the difficulties and strategies implemented by the teachers in contrast to the current institutional resolutions. As a result, the weaknesses and potential of this experience are pointed out.
\end{abstract}

Keywords: Pandemic. Journalism. Teaching.

\footnotetext{
${ }^{a}$ Universidade Federal do Amazonas. Amazonas/Brasil. E-mail: rafael.hoff@yahoo.com.br

${ }^{\mathrm{b}}$ Universidade Federal do Amazonas. Amazonas/Brasil. E-mail: crisb.jor@gmail.com
} 
Introdução

Em 2020, o mundo começou a enfrentar uma pandemia do novo vírus SarsCoV-19, em que o distanciamento social foi indicado por especialistas como a melhor medida para conter a disseminação do vírus. Com isso, a utilização da internet foi intensificada para todas as atividades, incluindo o ensino superior. Os docentes precisaram se adaptar às novas exigências do ambiente digital para ministrar aulas via internet, inclusive com a utilização de plataformas de redes sociais nas experiências didático-pedagógicas.

A educação digital faz parte do que Castells (2010) considera "sociedade da informação", contexto social em que a produção, o processamento e a transmissão da informação tornam-se fontes fundamentais de produtividade. Capra (2005) explica que "redes sociais são redes de comunicação que envolvem a linguagem simbólica, os limites culturais e as relações de poder”. O físico destaca que a tecnologia promoveu uma grande integração das comunicações, pela combinação de sons e imagens, com palavras escritas e faladas em um único hipertexto. "Uma vez que a cultura é criada e sustentada pelas redes de comunicações humanas, é inevitável que mude com a transformação dos seus modos de comunicação" (CAPRA, 2005, p. 163).

Assman (2004) indica que vivenciamos um momento em que o conhecimento, enquanto recurso humano, é o elemento norteador das relações sociais e esse período é representado por vários nomes: Sociedade da Informação (SI), Sociedade do Conhecimento (SC) e Sociedade Aprendente (SA). Temos então, na Educação Digital, uma possível solução para os desafios que tecnologias como o smartphone, o computador e a internet nos instigam a superar, ainda mais em tempos de calamidade mundial como a proporcionada pela Covid-19.

Assim, devido à necessidade do distanciamento social, em razão da pandemia do novo coronavírus, a universidade, assim como as demais atividades sociais e econômicas no Brasil e no mundo, tiveram que ser adaptadas. No caso da Universidade, que não será especificada com o intuito de preservar a identidade dos agentes envolvidos, houve a paralisação de atividades presenciais desde o início de março de 2020, como medida de combate à contaminação do vírus. Desse modo, conforme Resolução da Universidade, a oferta e a adesão, tanto discente quanto docente, ao Ensino Remoto Emergencial (ERE) se tornaram voluntárias, sem ônus a nenhuma das partes. 
As atividades didático-pedagógicas, segundo a orientação institucional, deveriam ser implementadas em um total de 15 encontros, sendo pelo menos seis síncronos, num período total de 75 dias entre os meses de setembro e dezembro de 2020. Implicou, ainda, na condição de que, em caso de reprovação do discente, a disciplina não seria computada no seu histórico escolar, podendo ele cursá-la novamente em outra oportunidade. Nesse contexto, este trabalho tem o objetivo de descrever a experiência vivenciada durante a pandemia do Covid-19 por dois professores do Magistério Superior na rede pública de ensino, durante o ERE, no curso de Jornalismo, ministrando a disciplina de Jornalismo Especializado.

O Relato de Experiência (RE) é apontado como método científico dentro das Ciências Humanas e, nesse caso, aplicado à discussão sobre as políticas, as práticas e os desafios docentes frente à adaptação ao sistema de ensino remoto, solução adotada institucionalmente e orientada por decisões governamentais para a manutenção dos serviços prestados pela universidade pública. O Relato de Experiência, neste caso,

\begin{abstract}
é uma modalidade de cultivo de conhecimento no território da pesquisa qualitativa, concebida na reinscrição e na elaboração ativada através de trabalhos da memória, em que o sujeito cognoscente implicado foi afetado e construiu seus direcionamentos de pesquisa ao longo de diferentes tempos. Isso posto, conjugará seu acervo associativo agindo processualmente, tanto em concomitância com o evento, como trazendo o produto processado pelas elaborações e em suas concatenações, e, finalmente, apresentará algumas das suas compreensões a respeito do vivido (DALTRO; FARIA, 2019).
\end{abstract}

O trabalho se justifica por esta consistir na primeira experiência institucionalizada de ensino integralmente remoto mediado pelas TIC digitais no referido curso, com mais de cinco décadas de operação. Carmo e Franco (2019) apontam que encontrar trilhas para a (re) construção da identidade profissional do educador pode torná-lo mais flexível à mudança em uma modalidade de educação em que sua experiência e seu conhecimento constituídos no magistério presencial podem se revelar insuficientes ou inadequados para o desenvolvimento da docência on-line.

O texto apresentado aqui divide-se na contextualização documental e no Relato de Experiência docente utilizando Tecnologias de Informação e Comunicação (TIC) aplicadas em um ensino mediado por estas, em ambiente digital, com atividades síncronas e assíncronas, para então discutir as dificuldades e as estratégias implementadas na busca do melhor aproveitamento nas práticas didático-pedagógicas com vistas ao processo de ensino-aprendizagem. Esse procedimento metodológico é afinado com o que propõem Daltro e Faria: 


\begin{abstract}
Numa arquitetura que busca alcançar sujeitos, acontecimentos e temporalidades, o Relato imbrica outros processos e saberes, ligados a modalidades de construções científicas mais aptas a reconhecer a importância da utilização das competências narrativas. Na medida de desconfianças, tensões políticas e consequente rebaixamento de discursos pretensiosos universalizantes - deflagrados por movimentos diaspóricos histórico/políticos - a potência narrativa chega como um modo de contar e de legitimar discursos sobre as singularidades como narrativas científicas competentes. Como já foi dito, o Relato demonstra a história, histórias e a importância de haver vozes plurais para contá-la (s) (DALTRO; FARIA, 2019).
\end{abstract}

Tem-se por objetivos o registro da experiência, bem como a reflexão crítica sobre a realidade imposta aos professores e estudantes num contexto de pandemia do novo coronavírus (Covid-19) durante o ano de 2020 em uma Universidade pública brasileira. Partindo das políticas públicas adotadas pelos gestores em âmbito federal e local, pretendemos apontar fragilidades, lacunas e potencialidades à implementação do Ensino Remoto Emergencial, tal como foi implementado na Instituição de Ensino Superior (IES).

\title{
Estrutura do Ensino Remoto Emergencial em Jornalismo Especializado
}

O percurso metodológico para a implementação da disciplina de Jornalismo Especializado envolveu a participação de dois professores doutores do curso, que iniciaram o trabalho com a definição de estratégias a serem desenvolvidas por meio do Plano de Ensino, aprovado na reunião do Colegiado no dia 03 de setembro de 2020. As aulas remotas passaram a ser oferecidas em duas modalidades: síncronas e assíncronas.
Ensinar remotamente não é sinônimo de ensinar a distância, embora esteja diretamente relacionado ao uso de tecnologia e, nesse caso, digital. $\mathrm{O}$ ensino remoto permite o uso de plataformas já disponíveis e abertas para outros fins, que não sejam estritamente os educacionais, assim como a inserção de ferramentas auxiliares e a introdução de práticas inovadoras. A variabilidade dos recursos e das estratégias bem como das práticas é definida a partir da familiaridade e da habilidade do professor em adotar tais recursos (GARCIA et al., 2020, p. 3).

No caso relatado, optou-se pela adoção da plataforma Google G-Suíte, com ênfase na função Sala de Aula (Classroom) para oferta sistematizada de conteúdo (vídeos, artigos em PDF, questões a serem respondidas, fóruns, links para e-books, entre outros) assíncrono. A curadoria do material partiu das referências bibliográficas já adotadas pelos docentes, e foi ampliada pela atualização de artigos e conteúdos multimidiáticos que pudessem complementar, ilustrar ou provocar a reflexão a partir das teorias abordadas. Depois de selecionados, os conteúdos foram disponibilizados para 
consulta assíncrona no Google Sala de Aula, em sala digital especificamente montada para a disciplina.

A segunda etapa consistiu na preparação das atividades on-line (e-atividades). Para Salmon (2004), e-atividade é uma palavra aplicada para uma estrutura de formação em linha ativa e interativa. As atividades devem ser motivadoras, cheias de propósito, baseadas na interação entre alunos, professores e participantes, majoritariamente mediante a contribuição em forma de mensagens e devem contar com um moderador. A sala de aula on-line no Google Classroom não consiste apenas em um repositório de conteúdo digital, mas um espaço dinâmico e ativo de interação e troca. Nesse sentido, foram elaboradas perguntas de múltipla escolha, perguntas abertas, suscitando a reflexão e a busca de embasamento teórico para as argumentações discentes. Também foram solicitados, como instrumentos avaliativos, relatórios sobre os webnários realizados durante o período letivo com profissionais atuantes no mercado local. Tais relatórios deveriam, no mínimo, apresentar uma proposta de diálogo com o referencial bibliográfico disponibilizado, na forma da incorporação de citação (curta ou longa, direta ou indireta) devidamente apontada segundo as normas da Associação Brasileira de Normas e Técnicas (ABNT).

Outros canais também foram acionados para integrar discentes e docentes: aplicativos (Whatsapp e Telegram), plataformas de compartilhamento de conteúdo (Facebook e Instagram) e de videoconferência para encontros síncronos (Google Meet e Zoom). Esses canais foram utilizados prioritariamente para a interação, permitindo o compartilhamento de links e conteúdos relacionados à disciplina, registro de atividades realizadas durante as aulas e troca de informações com o intuito de sanar dúvidas. Outra importante utilização desses canais foi o reforço positivo dedicado aos discentes para que completassem as atividades, interagissem e participassem dos encontros síncronos com os convidados.

Os encontros síncronos, além da experiência pelo Meet (plataforma do Google que permite interação por meio de áudio, vídeo e mensagens de texto via chat), foram gravados e disponibilizados (a partir de arquivo "baixado" automaticamente no Drive do Google vinculado à conta institucional dos docentes) para que os estudantes impossibilitados de comparecerem presencialmente pudessem acessar o material debatido, elaborando assim o relatório de atividade como ferramenta avaliativa. As atividades, dependendo da complexidade, contabilizaram quatro ou oito horas-aula, 
perfazendo as sessenta exigidas pelo Plano Pedagógico do Curso e orientações do MEC para essa disciplina.

A avaliação da disciplina foi composta de três notas, que somadas e divididas por três, resultaram na média final. A primeira avaliação consistiu na postagem dos relatórios sobre os webnários realizados na disciplina de maneira síncrona. Esses relatórios tinham como critérios de avaliação: a) a capacidade de relacionar teoria e prática; b) profundidade da discussão e avaliação crítica da experiência; c) discussão sobre aplicabilidade do conteúdo na formação acadêmica e profissional do estudante; d) organização e pontualidade. Cada relatório teve peso máximo de dois $(2,0)$ pontos, num total de cinco relatórios - Jornalismo Econômico, Jornalismo Político, Jornalismo Científico, Jornalismo Esportivo e Jornalismo Policial.

A segunda nota, de peso máximo dez $(10,0)$ estava relacionada à entrevista com um profissional (diferente daquele que participou do webnário), sobre a prática e o cotidiano, sobre as características e as demandas do profissional em termos de formação, bem como sobre os desafios e as dificuldades apresentados pela editoria em que trabalha. O conteúdo deveria ser autoral, na mídia que o estudante achasse mais confortável editar, desde que o conteúdo fosse postado editado e finalizado, incluindo ao final a ficha técnica de identificação do trabalho acadêmico, nomes dos professores coordenadores da atividade, identificação do entrevistador e entrevistado.

A terceira nota da disciplina, também com peso máximo dez $(10,0)$, consistiu em uma prova realizada pelo ambiente virtual, com questões fechadas de múltipla escolha e questões abertas, retomando o conteúdo de todo o semestre. Essas perguntas deviam ser respondidas em uma única abertura do sistema, não permitindo ao estudante "editar" suas respostas ao final e também impedindo a reabertura do sistema depois de fechado.

A disciplina foi ministrada às quartas, a partir das nove horas, reforçando que os encontros síncronos e a organização pessoal dos docentes e discentes deveriam reservar esse período para a realização das atividades. Ainda que muitas apresentassem um período (entre quarta e terça da semana seguinte) para a postagem de respostas ou relatórios, havia desde o início do período letivo um compromisso entre os matriculados e os professores para que houvesse regularidade e presença nas atividades neste dia e horário pré-estabelecidos.

\section{Relato de Experiência docente no ERE em Jornalismo}


A oferta da disciplina de Jornalismo Especializado na modalidade ERE foi definida a partir da mobilização e manifestação dos estudantes do sétimo período, em reunião de Colegiado do curso de Jornalismo realizada ainda no mês de agosto. Na oportunidade, as justificativas apresentadas pelos discentes foram: a) havia alta demanda reprimida pela disciplina; b) muitos estudantes finalistas dependiam apenas dessa disciplina e do Trabalho de Conclusão de Curso para concluírem a graduação. Diante do exposto, e mediante um cálculo prévio de quantos estudantes estariam na dependência dela para concluir a graduação, foram estipuladas vinte vagas.

Ao disponibilizar as duas primeiras atividades assíncronas, de leitura, pesquisa e interação pelo fórum como atividade de validação de presença, obteve-se um retorno de quatorze respostas na primeira e quatro na segunda. A diminuição das respostas na sala de aula digital é acompanhada pela baixa interação via grupo formado no Telegram, exclusivamente para a disciplina. No encontro síncrono realizado pelos professores, excepcionalmente e fora do calendário regular dessas atividades, como oportunidade para tirar dúvidas e motivar os estudantes a completarem as atividades, interagirem e participarem dos encontros previstos no cronograma, apenas quatro discentes compareceram (mesmo o encontro sendo oferecido no dia e horário previstos para a disciplina).

No início do semestre, todas as vagas foram preenchidas em uma semana, porém após o início das aulas e compartilhamento das atividades e cronogramas, o número de estudantes matriculados baixou para dezesseis e, destes, aproximadamente oito participam ativamente das atividades síncronas. Quatro estudantes matriculados nunca interagiram, entregaram os trabalhos avaliativos ou manifestaram qualquer dúvida pelos canais de interação. Outros quatro, pelo menos, diminuíram gradativamente a frequência de interação e não respondem aos chamados coletivos para postarem respostas às ferramentas avaliativas da disciplina no momento da escrita deste texto.

Apontamos como fator crucial para a manutenção do interesse e participação discente na proposta pedagógica do Ensino Remoto Emergencial a motivação. Segundo Silva (2014, p. 19),

Os professores precisam ser dinâmicos, ativos e voltados para a compreensão do universo dos alunos; a metodologia utilizada deve envolver o aluno no processo, tornando-o participante, porque não há Educação se o aluno não participa, se o aluno permanece apenas como observador. Uma das variáveis que induz à evasão é a prática de professores que tornam os alunos passivos, meros observadores distantes. 
A partir da contribuição de Silva, tomamos em perspectiva o protagonismo docente no exercício coletivo da motivação, da problematização e da experiência de aprendizagem. Podemos problematizar, a partir daí, a forma como o ERE foi implementado: um período letivo de 75 dias, com 15 encontros, sendo 6 síncronos (regras estabelecidas como mínimas para o curso nesta modalidade); mediado por Tecnologias de Informação e Comunicação; implementado a partir da definição em Colegiado, em 13 de agosto, tendo o primeiro encontro síncrono e apresentação do planejamento do semestre no dia 09 de setembro (menos de 30 dias); ausência de suporte técnico e tecnológico, tanto para professores quanto para os estudantes, a respeito do funcionamento, recursos e aproveitamento das ferramentas tecnológicas no processo didático-pedagógico.

Ainda que a IES tenha ofertado curso sobre utilização das ferramentas e aplicativos da plataforma Google para o ensino remoto e a distância, e que os dois professores que ministraram a disciplina tenham concluído o mesmo, em nenhum momento houve uma discussão pedagógica ou de estratégias didáticas a serem implementadas no ERE. Ainda que coubesse esse tipo de discussão às instâncias da coordenação de curso e da coordenação acadêmica da Faculdade de Informação e Comunicação, ou ainda à Pró-Reitoria de Ensino de Graduação (PROEG), os docentes foram lançados à experiência sem esse suporte. $\mathrm{O}$ resultado foi a implementação, em fase experimental, do processo de ensino remoto a partir dos recursos e capacidades individuais, somadas às percepções empíricas e intuições docentes daqueles que ministraram os conteúdos.

A mudança de ambiente físico para o exclusivamente digital, a falta de suporte institucional, tanto para sanar dúvidas quanto para oportunizar o melhor aproveitamento das ferramentas digitais no processo de ensino-aprendizagem, o esvaziamento de espaços de troca entre docentes (que na modalidade presencial ocorre nos eventuais encontros pelos corredores da IES, no cafezinho, na visita não programada à sala da coordenação ou dos colegas...) por conta da pandemia e o atraso na definição de início das atividades no ERE contribuíram para a instabilidade, a insegurança e, talvez, falta de motivação discente e docente no processo.

Contando que a suspensão das atividades presenciais e acadêmicas ocorreu no início de março de 2020, a retomada de atividades cinco meses depois (agosto, com o anúncio do ERE) de forma voluntária e sem consequências ao histórico escolar, contribuiu para a flexibilização quanto ao compromisso com a disciplina, com os 
conteúdos e processos avaliativos. A lacuna temporal de cinco meses em que os estudantes, em situação de quarentena ou não, puderam adotar atividades e compromissos de outras ordens, inclusive para a manutenção da saúde mental, sinaliza que a tomada de decisão institucional pela adesão ao ERE foi tardia e pouco planejada.

Temos, então, a oportunidade de voltar o olhar para o ensino e para o trabalho docente nesse contexto. Witter (2000) aponta fatores que contribuem para a desmotivação dos professores:

a formação, ou a falta de formação adequada, os baixos salários, a desvalorização social do professor, as condições materiais em que se vê compelido a trabalhar, a falta de um sistema adequado de reforços (ou recompensas) pelo empenho em concretizar um bom trabalho, a diversidade dos alunos, a falta de uma boa administração do tempo, planejamentos deficientes, a sobrecarga de trabalho (em número de alunos, de turmas e até de escolas em que atua), a falta de envolvimento com os alunos, entre outras variáveis a que estão sujeitos, conduzem à apresentação de respostas de manutenção da situação atual, de falta de iniciativa, de desinteresse pela mudança e não engajamento efetivo em qualquer inovação" (WITTER apud LIMA, 2000, p. 160).

Dentre esses pontos destacados pela citação, damos atenção à "falta de formação adequada", "desvalorização social do professor" e as "condições materiais em que se vê compelido a trabalhar". Isso porque, num período de pandemia do Covid-19, mesmo em quarentena, os professores estão sujeitos às situações de angústia gerados pela incerteza sobre o futuro mediante a falta de vacinas e tratamentos eficazes, à tristeza pela perda de parentes e amigos pelo agravamento dos sintomas da doença causada pelo vírus, à instabilidade emocional gerada pelo contexto político nacional que sinaliza para uma desvalorização da classe trabalhadora do ensino, somada à ameaça de uma reforma administrativa que sinaliza possibilidades como cortes de salários, congelamento de progressões, entre outras medidas que atingem diretamente o funcionalismo público, incluindo os docentes.

Esses fatores, de cunho psicológico, são somados aos fatores de ordem material: trabalhar com equipamentos pessoais nem sempre adequados à atividade docente de ensino remoto (conexão falha de internet, falta de câmera ou fones de ouvido para melhor interação com as pessoas conectadas, cadeiras impróprias ao trabalho remoto em longas jornadas); aumento substancial na conta de energia devido ao trabalho que era desenvolvido na universidade e passou ao ambiente domiciliar, sem nenhum tipo de compensação financeira, exigindo por consequência o redimensionamento do orçamento familiar; adaptação da residência, tanto quanto possível, para o desempenho das atividades docentes, por vezes implicando na incorporação de elementos que 
causam ruído no processo de ensino-aprendizagem pela distração (cachorro latindo, vizinho realizando uma reforma, trânsito etc.).

Associada à usabilidade e cultura dos estudantes no trato com os dispositivos e artefatos digitais, temos a presencialidade, materialidade e o dispositivo do "deletar", desativar, desabilitar, desligar como possibilidade para a resolução de tensões presentes na experiência escolar. Se o conteúdo é de difícil compreensão, a aula mediada pelas TIC concorre com outras atividades de maior interesse ou relevância, é natural que haja um desvio, uma conduta de "anulação" daquele estímulo que não condiz com o prazer gerado pela aprendizagem na experiência didático-pedagógica. Nesse caso, desabilitar a câmera do dispositivo utilizado para "demarcar a presença" em encontros síncronos permite que os usuários realizem outras atividades de maior interesse, "mascarando" essa presença, por exemplo. Outra possibilidade é a evasão, o abandono da regularidade do ensino formal que exige acompanhamento dos conteúdos e atividades, obediência a um cronograma, autodisciplina para sistematização dos processos de aprendizagem, entre outras.

\section{Tensionamentos e críticas ao ERE em Jornalismo}

Um dos principais desafios dessa modalidade foi a instabilidade da internet na capital que, por vezes, interrompeu a conexão durante as aulas síncronas. Além disso, por ser falha e deficitária, a rede disponível dificultou o acesso dos estudantes aos arquivos com conteúdo didático disponibilizados na sala de aula digital. Ainda que a conectividade fosse boa, tivemos o fato de que muitos estudantes acessaram esses conteúdos pelos smartphones, com capacidade de memória menor do que notebooks e desktops, além de dependerem - muitas vezes - de pacotes de dados móveis, rapidamente consumidos no processo de download e/ou participação síncrona nos encontros.

Alguns pontos ainda carecem de discussão: a) a implementação do ERE; b) a falta de suporte por parte da IES; c) o contexto da educação superior pública no Brasil; d) a política institucional da IES sobre a avaliação do ERE; e) os riscos da institucionalização do ERE.

Quando levantamos como ponto de discussão a montagem de um Ensino Remoto Emergencial em que o período entre a definição em colegiado de quais disciplinas seriam ofertadas, matrícula dos estudantes e início das aulas ficou restrita a 
menos de trinta dias, reforçamos que essa implementação dificultou o trabalho de pesquisa, curadoria e preparação das aulas em uma modalidade diferente daquela aplicada até então nas aulas de Jornalismo da IES.

Isso poderia implicar num hiper ou hipodimensionamento dos conteúdos, das referências, trazendo prejuízo ao processo de ensino-aprendizagem. Conteúdos "a mais" poderiam assustar o estudante que, pela primeira vez, se deparava com tal sistema de ensino-aprendizagem no Jornalismo. Por outro lado, a falta de conteúdos e referências poderia não contemplar os objetivos e conteúdos da disciplina, tal como proposto na ementa e no planejamento dos professores. A implantação experimental e insegura, levou os dois docentes a um hiperdimensionamento, procurando ofertar conteúdos complementares e flexibilização na cobrança de atividades que demonstrassem a relação teoria-prática. Porém, uma evasão nítida que pode ser relacionada e esse fator (em avaliação da disciplina ao final do semestre, a quantidade de material disponibilizado motivou alguns estudantes a desistirem da disciplina).

A segunda questão levantada aqui como problematização é que não houve uma preparação sistematizada, nem por parte dos estudantes, nem por parte dos professores, para dominar as ferramentas e canais de interação no sistema ERE - todo curso de aperfeiçoamento até então ofertado foi por adesão voluntária, conforme disponibilidade e interesse de cada professor -, podendo resultar em experimentações ou produção via "tentativa-e-erro" que eventualmente fragilizaram a imagem institucional (do docente, do curso e da Universidade). Além disso, várias perguntas de ordem técnica ficaram sem resposta: a) como os docentes deveriam proceder em caso de interrupção da internet durante os encontros síncronos? b) como proceder em caso de falha técnica da plataforma, impedindo a gravação e disponibilização dos encontros síncronos gravados aos estudantes que não comparecessem ao mesmo, para a entrega das atividades avaliativas? Isso sem contar que em nenhum momento a IES discutiu ou preparou os docentes do Jornalismo à adesão de estratégias como Metodologias Ativas, Sala de Aula Invertida e práticas didático-pedagógicas.

O terceiro ponto que levantamos para essa discussão diz respeito às incertezas geradas pelo cenário político em 2020 (em que o governo se mobilizava por uma reforma administrativa calcada em um "enxugamento" da máquina estatal, em que 
professores da rede pública foram chamados de "parasitas"1) que, mesmo sinalizando institucionalmente a "adesão voluntária", geraram dúvidas sobre possíveis implicações administrativas e financeiras àqueles que não aderissem ao ERE. Soma-se a esse cenário a insegurança gerada pela condição de estágio probatório dos dois professores ministrantes da disciplina, que optaram pela adesão voluntária sob o risco de avaliação negativa dos pares ao "chamamento" da IES para a manutenção das atividades de ensino da graduação no período.

O quarto ponto destacado trata da fragilidade do argumento apresentado pela Universidade para a oferta do ERE, uma vez que os docentes foram orientados por suas coordenações - em reunião de Colegiado - a ofertarem prioritariamente as disciplinas de início de curso. $\mathrm{O}$ argumento consistia na defesa de que, diante de um eventual retorno às atividades presenciais, haveria diminuição do número de estudantes em aula e maior facilidade na aplicação de orientações e medidas de biossegurança como o distanciamento social. Esse argumento defendia que se as disciplinas fossem ofertadas, haveria adesão por parte dos calouros. Porém, os estudantes poderiam aderir voluntariamente ao ERE, sem ônus às suas carreiras acadêmicas, não havendo garantia de nenhum percentual de adesão e, por conta disso, nenhuma diminuição significativa de estudantes na sala de aula em caso de retorno presencial. Outro ponto crucial nessa discussão é que a IES parece não ter consultado os próprios estudantes para tal argumentação. Quando consultados nas reuniões de Colegiado que antecederam o ERE, os calouros que responderam ao questionamento realizado pelo Centro Acadêmico de Jornalismo apontaram para a não adesão às disciplinas nessa modalidade.

Por fim, mas não menos importante, é a possibilidade de que o ERE funcionasse como um "termômetro" para a adoção compulsória e generalista da modalidade de Ensino a Distância ou mesmo do Ensino Remoto nos cursos de graduação da rede pública, uma vez que aponta para uma diminuição das despesas fixas institucionais (energia, internet, limpeza etc.), já que o trabalho docente passou a incrementar as despesas domésticas como o aumento nas contas de energia (já que as dependências da Universidade estão fechadas e os professores impossibilitados de trabalharem em seus gabinetes), manutenção de equipamentos e acesso à internet sem uma contrapartida do governo e suas instâncias. Essa métrica quantitativa e de redução

\footnotetext{
${ }^{1}$ Tal como registra a reportagem do Jornal Nacional disponibilizado pelo portal de notícias G1: https://g1.globo.com/jornal-nacional/noticia/2020/02/07/paulo-guedes-compara-servidores-publicos-comparasitas.ghtml .
} 
de despesas ganhou eco nas políticas públicas de corte nos orçamentos da IES $^{2}$, tornando-se perigosamente interessante ao atual governo que as Universidades mantivessem o sistema remoto e a distância permanentes entre suas ofertas.

Outra frente, associada a esses contextos político e econômico que envolveram o ensino superior no país, são as mobilizações direcionadas à reformulação da base nacional curricular para o Jornalismo.

Os debates no mundo do jornalismo colocam a questão do ensino em posição
de destaque: as discussões nesta área têm se pautado pela adoção e
implementação das Novas Diretrizes Curriculares do Jornalismo (BRASIL,
2013), que trouxeram à pauta acadêmica o antigo confronto entre teoria e
prática. Na visão de alguns pesquisadores como Marcondes Filho (2014), em
entrevista à Revista Cult, as Novas Diretrizes estabelecem uma desvinculação
na formação do jornalista da cultura científica e humanística da área de
comunicação. De outro modo, as diretrizes impõem cada vez mais, um
domínio técnico e uma aproximação com o mercado profissional (SILVA;
LOPES, 2016, p. 138-139).

O primeiro impacto, vivenciado em 2013, resultou na transformação dos cursos de Comunicação Social, com habilitações em Jornalismo, Publicidade e Propaganda, Relações Públicas, Produção em Mídia Audiovisual, Editoração, entre outras, em cursos independentes. Agora, as propostas são direcionadas a uma diminuição dos conteúdos programáticos das disciplinas e aumento da aproximação entre Universidade e sociedade. Se por um lado esse movimento pode ser visto como positivo pela popularização da ciência e tecnologia, por outro deve ser tratado cautelosamente, já que a aproximação do governo federal com os modelos norte-americanos pode também influenciar a transformação do curso de Jornalismo em uma especialização (perdendo o status de graduação e a obrigatoriedade de 2.700 horas-aula divididas entre formação geral humanística e específica). Essa transformação, possível, impacta diretamente sobre a imagem e o pensamento corrente do Jornalismo como uma área estratégica da comunicação, para a cidadania e para a defesa dos direitos fundamentais dos brasileiros. Transformada em especialização, não haveria a obrigatoriedade de formação nas áreas da Ética, da Sociologia e da Filosofia, tão ricas à prática saudável e responsável da profissão.

\section{Considerações finais}

\footnotetext{
${ }^{2}$ Tal como aponta a matéria da revista Exame, disponível no link https://exame.com/economia/coronavirus-faz-usp-unesp-e-unicamp-perderem-ao-menos-r12-bilhao/.
} 
Apesar dessas questões que tensionam a motivação discente e docente sobre o ensino de Jornalismo, o conteúdo programático elaborado para a disciplina de Jornalismo Especializado tentou dar cobertura à complexidade da ementa e suas particularidades, dinâmicas mercadológicas, além de proporcionar ao estudante uma troca de experiência com profissionais em atuação na região em que se localiza a IES. Para tanto, contou com a participação de cinco jornalistas graduados e atuantes nos veículos e assessorias de imprensa. Após explanação de suas atividades e percepções sobre o mercado, responderam às perguntas dos estudantes em um momento de interação síncrona.

A mescla de estratégias e recursos didático-pedagógicos procurou explorar as diferentes habilidades, tempos e percepções dos jovens a respeito das diferenças entre teoria e prática, desafios e estado da arte no mercado regional, bem como aprofundar conhecimentos específicos de algumas editorias selecionadas pelos professores, sinalizando a diversidade e a possibilidade de novos aprendizados a partir do conteúdo visto na graduação.

Com o ERE aplicado ao ensino superior de Jornalismo em uma Universidade Federal, percebeu-se que a perspectiva do aluno no processo de aprendizagem em ambiente virtual implica em aprender coletivamente e ativamente, responsabilizando-o pelo processo de aprendizagem. Essa perspectiva se opõe àquela que olha para o ensino como elemento mais importante da Educação formal, em que o professor é convocado a (re)inventar estratégias e recursos, on e off-line, como se o determinismo do processo recaísse sobre as tecnologias e suas aplicações. A evasão, a baixa aderência às atividades síncronas e a pouca interatividade pelos canais digitais criados para a disciplina demonstraram a importância da interação como elemento motivador, assim como sugerem que o tempo da tomada de decisão - de âmbito político e institucional sobre a manutenção das atividades no sistema de Ensino Remoto Emergencial pareceram desconectados da realidade vivida por esses estudantes. No aguardo de uma definição entre março e agosto de 2020, muitos vincularam-se a estágios e empregos, matricularam-se em cursos ou aderiram a projetos para além das disciplinas, concorrendo com estas no que diz respeito ao interesse, refletido na (des)motivação.

Mesmo com as aulas proporcionando atividades que os desafiassem, que instigassem as suas capacidades de criar e resolver problemas, bem como permitissem a interação, a troca e a valorização de experiências pessoais no decorrer das aulas, a falta de um suporte ou atenção institucional ao processo de aprendizagem deu espaço para 
um ensino esvaziado de sentido. Nem os recursos foucaultianos de controle (atividades valendo presença, atividades avaliativas, presença em encontros síncronos) aplicados às relações entre docentes e discentes foram suficientes para manter a presença, quiçá o interesse. Vale ressaltar que os estudantes, na maioria, pertenciam ao sétimo período e dependiam da disciplina de Jornalismo Especializado e da orientação do Trabalho de Conclusão de Curso para concluírem a graduação, o que poderia servir de um elemento motivador pessoal.

Ainda que Silva e Lopes (2016) apontem caminhos para o constante aperfeiçoamento docente mediante as transformações do mercado jornalístico, em meio a uma pandemia em que o distanciamento social é a medida mais indicada de biossegurança, parece ser um desafio conciliar tais proposições:

\begin{abstract}
atitude primordial para nortear racionalmente a atividade pedagógica, faz-se premente a readequação dos professores às necessidades da nova lógica produtiva. Assim, compreendemos que apenas fazer estudos, pesquisas e análises sobre o jornalismo e a comunicação não bastam. É preciso ir além, e de fato "meter a mão na massa", realizando capacitações e cursos de aprimoramento que viabilizem uma experiência prática do fazer jornalismo nestes novos contextos. Nesse sentido, fomentar parcerias entre instituições de ensino e empresas e demais organizações de comunicação, avançando em um processo de educação corporativa por um lado e de educomunicação por outro, poderiam ser alternativas viáveis para sanar estas demandas surgidas nos últimos anos. (SILVA; LOPES, 2016, p. 150)
\end{abstract}

A proposta de uma aproximação entre as demandas de um mercado dinâmico, que incorpora com rapidez novas práticas e tecnologias que afetam o fazer jornalístico, também acarreta na necessidade de constante reflexão crítica sobre tais práticas. $\mathrm{O}$ risco de manter como foco essa adequação mercadológica é, de imediato, fragilizar o processo de reflexão e tratamento acadêmico / científico de tais eventos, dinâmicas e relações. Sem a organização e o tratamento desses saberes, corremos o risco de formar "peças de reposição" em um mercado tecnicista, que valoriza o domínio sobre softwares e a produção de conteúdo em múltiplas linguagens, em detrimento da apuração dos fatos, do compromisso com a verdade e com a ética. Tais desafios, desde o início da formação superior em Jornalismo, são colocados como balizas que sustentam a necessidade dessa formação de maneira ampla, humanística e crítica, em oposição às correntes mais instrumentalistas do ensino.

Dutra e Faria (2019) enfatizam a respeito do Relato de Experiência e seu aspecto científico: "a singularidade assume a afirmação de criação cognoscente. O sujeito utiliza equações disponíveis em si e fora de si, mas, ao falar, é falado por um repertório que estabelece suas marcas discursivas". Como apontamentos possíveis para 
um diálogo interno entre docentes, cabem questões relativas às estratégias didáticopedagógicas, ao tempo de tomada de decisão institucional e sobre a aplicação de ações para a manutenção dos trabalhos docentes, bem como uma discussão sobre as demandas e os suportes necessários ao bom andamento das atividades nessa modalidade de ensino. 


\section{Referências}

ASSMAN, H. Reencantar a educação - rumo à sociedade aprendente. 8 ed. Petrópolis: Vozes, 2004.

CAMPOS, D.M. de S. Psicologia da aprendizagem. 23. ed. Petrópolis: Vozes, 1993.

CARMO, R. O.S.; Franco, A.P. Da docência presencial à docência on-line: aprendizagens de professores universitários da educação a distância. Educação em Revista, v. 35, p. 1-29. Online: 2019. DOI: http://dx.doi.org/10.1590/0102-4698210399.

CAPRA, F. As conexões ocultas: ciência para uma vida sustentável. Trad.: Cipolis, M.B. São Paulo: Cultrix, 2005.

CASTELLS, M. A sociedade em rede. São Paulo: Paz e Terra, 2010.

DALTRO, Mônica Ramos; FARIA, Anna Amélia de. Relato de Experiência: uma narrativa científica na pós-modernidade. Revista Estudos \& Pesquisa em Psicologia. v.19, n.1. Rio de Janeiro: 2019. Disponível em: https://www.epublicacoes.uerj.br/index.php/revispsi/article/view/43015/29664 . Acesso em: 26 ago. 2021.

FIUZA, P.J. Aspectos motivacionais na educação a distância: análise estratégica e dimensionamento de ações. Dissertação apresentada ao Programa de Mestrado em Engenharia de Produção da Universidade Federal de Santa Catarina. Florianópolis: 2002. Disponível em: https://core.ac.uk/download/pdf/30364095.pdf. Acesso em 10 out. 2020.

GARCIA, T.C.M; MORAIS, I.R.D.; ZAROS, L.G.; RÊGO, M.C.F.D. Ensino Remoto Emergencial: proposta de design para organização das aulas. Natal: SEDIS-UFRN, 2020. Disponível em: https://www.progesp.ufrn.br/storage/documentos/1MYt6NuPXEA8Zz0ltLH4BanyEKLlj5WkH PWUbzD7.pdf. Acesso em 10 out. 2020.

SALMON, G. E-actividades. El factor clave para uan formación en línea activa. Barcelona: Editorial UOC, 2004.

LIMA, L.M.S. Motivação em sala de aula: a mola propulsora da aprendizagem In: OLIVEIRA, G.C.; FINI, L.D.T. Leituras de Psicologia para Formação de Professores. Petrópolis, RJ: Vozes; Bragança Paulista, SP: Universidade São Francisco, 2000.

SILVA, G.B. da. O papel da motivação para a aprendizagem escolar. Monografia apresentada ao curso de Especialização em Fundamentos da Educação: Prática Pedagógicas Interdisciplinares. João Pessoa: UFPB, 2014. Disponível em: http://dspace.bc.uepb.edu.br/jspui/bitstream/123456789/9644/1/PDF\%20\%20Geruza\%20Barbosa\%20da\%20Silva.pdf. Acesso em: 05 out 2020.

SILVA, R.P. da.; LOPES, B.B. Mudanças estruturais e ensino de jornalismo: o papel do professor nos novos rumos do jornalismo brasileiro. Revista Intexto. Porto Alegre, UFRGS, n. 35, p. 137-153, jan./abr. 2016. Disponível em https://seer.ufrgs.br/intexto/article/viewFile/58110/37264. Acesso em: 22 nov 2020.

\footnotetext{
' Doutor em Ciências da Comunicação e Informação pela Universidade Federal do Rio Grande do Sul (2018). É pesquisador no Grupo de Pesquisa em Processos Audiovisuais (ProAv) UFRGS, do Grupo de Ações e Investigações Autopoiéticas (GAIA) - UNISC e coordenador do
} 
Grupo de Pesquisa em Processos Imagéticos (PRIMA) - UFAM. Docente do curso de Jornalismo da UFAM e professor permanente do Programa de Pós-Graduação em Comunicação da UFRR.

ii Docente do curso de Jornalismo da UFAM, pesquisadora do Grupo de Pesquisa Comunicação, Cultura e Amazônia (Trokano). 